\title{
A morte do senhor e o destino das famílias escravas nas partilhas. Campinas, século XIX
}

Cristiany Miranda Rocha

UNICAMP

\section{RESUMO}

Este artigo tem como objetivo enfatizar a importância do estudo das partilhas dos inventários na avaliação do impacto da morte dos senhores sobre os núcleos familiares dos seus cativos. Essa questão é de grande relevância para o estudo do parentesco escravo, uma vez que a freqüência nas separações de casais ou filhos está diretamente ligada à relevância dos altos índices de casamentos identificados pela historiografia. Além disso, o artigo chama a atenção para a importância de uma metodologia de entrecruzamento de vários tipos de fontes para um mesmo grupo de cativos, tanto para o mapeamento dos grupos de parentesco, quanto para a apreensão dos destinos deles na divisão dos bens dos seus proprietários.

Palavras-chave: Escravidão; Família escrava; Inventários post-mortem.

\section{ABSTRACT}

This article has as objective to emphasize the importance of the inventory apportionments study in the evaluation of impact of the masters' death on the nuclear family of their captives. This question is of great importance for the study of the slave kinship, once that the frequency, in which the separation of couples or children has occurred, is directly connected to the importance of the high rates of marriages identified by historiography. Besides, the article points out the importance of a crossover methodology of several kinds of sources for the same group of captives, not only for the mapping of the kinship groups, but also for the apprehension of their fates in division of their owners' properties. Keywords: Slavery; Slave family; Postmortem inventories.

Os estudos mais específicos sobre a família escrava surgiram no Brasil, na década de 1970, através de abordagens demográficas. ${ }^{1}$ Nelas, os autores analisaram, principalmente, as listas nominativas dos censos antigos (feitos em São Paulo entre o final do século XVIII e a primeira metade do XIX), as 
cópias das listas de matrícula anexadas aos inventários e os registros paroquiais de casamentos e batismos de escravos feitos pela Igreja católica. O objetivo principal desses trabalhos era o de contestar as conclusões apontadas por estudos publicados, sobretudo na década de 1960, por um grupo de intelectuais que ficou conhecido como a "Escola Paulista de Sociologia".

De um modo geral, esses últimos buscaram enfatizar o caráter violento e opressor da escravidão no Brasil, que, por sua vez, teria destruído todas as normas e referências de comportamento social e familiar dos escravos, impedindo a existência de qualquer tipo de solidariedade duradoura entre eles. ${ }^{2}$ Segundo Florestan Fernandes, os efeitos morais nefastos daquele sistema de produção se fizeram sentir sobre os cativos mesmo no período pós-abolição. Em seu estudo sobre a "integração do negro" ao mercado de trabalho nascente, no início do século XX, ele concluiu que a imensa miséria material e moral que acompanhou o liberto e seus descendentes desde os tempos do cativeiro teria impedido que estes concorressem em pé de igualdade com os imigrantes europeus recém-chegados. Essa "herança do cativeiro", que tornava o negro incapaz de ascender socialmente - condenando-o ao alcoolismo, à prostituição, ao desemprego e às piores moradias —, tinha como principal elemento a ausência de laços familiares e uma conseqüente promiscuidade generalizada no interior das senzalas e, posteriormente, dos cortiços da cidade de São Paulo. Nas palavras desse autor, foi

a própria família que não se constituiu e não fez sentir seu influxo psico-social e sócio-cultural na modelação da personalidade básica, no controle de comportamentos egoísticos ou anti-sociais e na criação de laços de solidariedade moral. Comprova-se isso, historicamente, por uma simples referência à política central da sociedade senhorial e escravocrata brasileira, que sempre procurou impedir o florescimento da vida social organizada e da família como instituição integrada no seio da população escrava. ${ }^{3}$

Portanto, nesta perspectiva, as dificuldades enfrentadas pelos negros no período pós-abolição para se integrarem à "sociedade de classes" advinham, em última instância, da ausência do "influxo psico-social e sócio-cultural” da família, desde os tempos do cativeiro. Entretanto, Fernandes não apresenta nenhum tipo de fonte que comprove "historicamente" essa "política central da sociedade senhorial e escravocrata”, que visava impedir a formação de famílias entre a população escrava, nem tampouco mostra evidências da eficácia de tal "política". Além disso, se os trabalhadores negros eram preteridos 
pelos imigrantes europeus e brancos, no mercado de trabalho do início do século XX, o preconceito racial dos empregadores parece ser uma explicação mais plausível do que a falta de organização familiar entre os escravos.

Procurando contestar essas imagens cristalizadas por essa historiografia de cunho sociológico a respeito da vida familiar dos cativos no Brasil, a partir de meados da década de 1970 começaram a surgir trabalhos demográficos que atestavam empiricamente a formação de núcleos familiares entre os escravos. Como vimos, esses estudos fizeram uso de várias fontes quantitativas, como os censos antigos (listas nominativas de habitantes) e os registros paroquiais. Tais pesquisas demonstraram que o casamento religioso e a estabilidade das uniões conjugais entre os cativos não eram meras exceções no contexto escravista. ${ }^{4}$

Todavia, a maioria dos historiadores que se dedicaram ao estudo do tema considera que a duração dessa estabilidade dos laços familiares dos escravos, em geral, teria coincidido com o tempo de vida dos proprietários. ${ }^{5} \mathrm{~A}$ ocasião da morte de um senhor e a conseqüente partilha dos seus bens são consideradas pela historiografia como circunstâncias de grande apreensão para as famílias de cativos, tendo em vista as incertezas acerca de seus destinos. Este artigo analisa as partilhas dos inventários post-mortem de sete proprietários da região de Campinas (SP), no século XIX, na intenção de investigar até que ponto a morte do senhor efetivamente rompia a união da família cativa, pelas separações de familiares entre os herdeiros ou pela sua venda para a quitação de dívidas da herança. ${ }^{6}$ Para uma identificação mais ampla dos núcleos familiares recorremos ao cruzamento das informações dos inventários com aquelas provenientes de outras fontes, como os registros de batismos. Além disso, buscamos conhecer um pouco das famílias dos proprietários, combinando as informações dos inventários de mais de um membro delas.

Avaliar a incidência dessas separações tem fundamental importância para compreender as expectativas que os cativos podiam ter em relação à estabilidade e união de seus núcleos familiares, ao longo do tempo. Afinal, podemos considerar que, caso tenha existido uma prática relativamente comum de se repartir os escravos de uma herança sem levar em conta as ligações familiares entre eles, ela não teria passado despercebida aos cativos. E sendo assim, tal costume funcionaria como um fator de inibição à constituição de famílias, principalmente à busca pelo casamento religioso por parte dos escravos. Além disso, e não menos importante, se a duração das uniões estava limitada ao tempo de vida restante ao proprietário, os altos índices de casamentos en- 
contrados pela historiografia, ${ }^{7}$ para a região estudada, seriam pouco relevantes, já que boa parte dessas uniões estaria fadada a uma duração efêmera.

Campinas foi escolhida como cenário dessa análise por se tratar de um município que concentrava boa parte do contingente escravo do Oeste Paulista ao longo do século XIX. No ano de 1829, a economia desse município era dominada pelos engenhos de açúcar, e cerca de 49,4 por cento dos escravos estavam vivendo em grandes propriedades (com 50 ou mais cativos), de acordo com os dados das Listas nominativas de habitantes daquele ano. Já na segunda metade do século XIX, os engenhos foram substituídos pelos grandes cafezais e a posse de escravos se tornou ainda mais concentrada, com o fim do tráfico de africanos em 1850 e a alta nos preços dos escravos. Em 1872, por exemplo, a maioria dos escravos $(64,6 \%)$ vivia em grandes fazendas, segundo o estudo de Robert Slenes. ${ }^{8}$ Portanto, nossa opção por médias e grandes propriedades, de certa forma, diz respeito às experiências possíveis para grande parte da população cativa daquela região na segunda metade do século XIX.

\section{OS ESCRAVOS NAS PARTILHAS: OS LIMITES \\ DA ESTABILIDADE E DA PROPRIEDADE}

No inventário do capitão Francisco José de Camargo Andrade, foram partilhados 208 cativos entre os 11 herdeiros e a viúva inventariante. Nenhum casal legalmente constituído foi separado na partilha. Entretanto, quatro crianças com menos de 10 anos de idade e uma jovem de 15 foram dadas a herdeiros diferentes daqueles que receberam seus pais. Em todos os casos, esses cativos fizeram parte do pagamento a herdeiros menores, que por sua vez, residiam em companhia de D. Maria Luiza Teixeira Nogueira, a viúva do capitão.

A herdeira menor, D. Francisca, tinha 10 anos de idade e recebeu em seu quinhão a escrava Justina, de 15, filha de Modesto e Narciza Torta. Esse casal fez parte da meação da inventariante. Portanto, na prática, não houve a separação dessa família, tendo em vista a coabitação entre os herdeiros. Caso semelhante foi o do menino Tito, de 7 anos de idade, filho do casal de cativos Joana e Reginaldo. Enquanto estes foram herdados por D. Maria Luiza, Tito foi dado em pagamento ao herdeiro menor Floriano, com idade de 5 para 6 anos, e que também vivia com sua mãe. Do mesmo modo, o herdeiro Luciano, que contava "mais ou menos" 7 anos à época do inventário, recebeu o escravinho Roberto, de 6 para 7 anos, filho de Fermina e Leocádio, os quais foram herdados pela inventariante. 
A mesma sorte não teve a pequena Benedita, de 8 anos. Ela fez parte do pagamento à herdeira menor Olívia, de apenas 4 anos de idade (que também residia com D. Maria Luiza), ao passo que seus pais, Narciza e Januário, além da irmã Valentina, de 4 anos, foram incluídos no quinhão que coube ao herdeiro João Novaes de Camargo Andrade. Este, por sua vez, ao final da partilha, apresentou um requerimento ao Juiz de Órfãos solicitando que a escrava Valentina, que lhe foi dada em partilha, fosse entregue à sua irmã Olívia, conforme já havia sido pedido (provavelmente pelo tutor), "em virtude de sua idade estar muito própria para a mesma órfã”. ${ }^{9}$ Dessa forma, as duas irmãs, Benedita e Valentina, permaneceram juntas, porém, separadas de seus pais.

Por que isso teria ocorrido, apesar de haver 208 escravos a serem partilhados? Afinal, não era o caso de uma pequena posse, na qual fosse necessária a separação de familiares cativos para o pagamento aos herdeiros de suas legítimas. A primeira explicação que ocorre é a de que aqueles proprietários não estavam preocupados com a manutenção da união daquela família de cativos. Além disso, queriam dar a cada herdeiro menor pelo menos uma criança escrava na mesma faixa de idade.

Não sabemos por que os pais de Benedita e Valentina não foram incluídos na meação da viúva, como aconteceu com os pais das outras crianças e da jovem Justina. Procuramos, então, saber um pouco mais sobre o herdeiro João Novaes. Esse filho do capitão era "maior de 21 anos" e solteiro à época do inventário, vivendo num sítio chamado "Casinha”. As terras desse sítio, por sua vez, haviam sido "desencravadas" do sítio Sertão, que era a maior propriedade da família, onde residia a viúva, D. Maria Luiza. Desse modo, a propriedade de João Novaes fazia divisa com a fazenda da sua mãe. Portanto, Benedita e sua irmã seriam ao menos vizinhas de seus pais depois da partilha, podendo encontrá-los, talvez, com relativa freqüência, tendo em vista a proximidade geográfica e o parentesco entre aqueles senhores.

A Lei de 28 de setembro de 1871 proibiu a separação de casais ou de pais e filhos menores de 12 anos, fosse por venda, herança ou doação. ${ }^{10}$ A partilha que acabamos de mencionar aconteceu em 1870, e, muito embora não houvesse necessidades econômicas que justificassem a separação daquela família, esta ocorreu, ainda que os novos proprietários fossem vizinhos. A vontade senhorial de entregar um pequeno escravo a cada pequeno herdeiro do capitão parece ter sido o único ou principal motivo para tal atitude.

Assim sendo, podemos pensar que para esses proprietários a preservação das famílias cativas na distribuição dos escravos entre os herdeiros era uma regra a ser observada. Afinal, com exceção da família de Benedita e Valentina, 
todas as outras permaneceram unidas depois da partilha. Havia, portanto, a intenção de manter os núcleos familiares unidos. Todavia, essa intenção ou regra geral tinha seu limite fixado nos interesses e caprichos senhoriais, que podiam variar de acordo com o momento do ciclo de vida da família de proprietários.

Quando foi aberto o inventário de Manuel Joaquim de Moraes, em 1883, ele já era viúvo, e seus bens foram partilhados pelos sete herdeiros, todos maiores de 21 anos. Situação bem diferente daquela vista no caso anterior, onde tínhamos uma viúva (que recebia a "meação", isto é, metade do valor líquido da herança) e herdeiros menores.

Desta vez, foram avaliados e partilhados 88 cativos. Novamente, nenhum casal foi separado entre os herdeiros. Nesse ano, não havia escravos com menos de 13 anos de idade naquela posse, segundo o inventário. ${ }^{11}$ De um modo geral, os grupos familiares não sofreram separações de membros ${ }^{12}$ com idades abaixo dos 21 anos, com exceção de três moças. Marcelina, de 15 anos, foi dada a um herdeiro diferente daquele que recebeu seus pais, Severino e Apolinária, e seus irmãos Olympio e Catharina. Do mesmo modo, a escrava Rufina, de 18 anos, foi separada dos pais e do irmão de 16 anos. A terceira foi a escrava Luiza, de 20 anos, cujos pais já haviam falecido e que viu seus cinco irmãos e dois sobrinhos irem para outra propriedade.

Levando em conta o grande número de escravos ligados a redes de parentesco naquela propriedade, o número de separações foi consideravelmente baixo. Dentre os 88 cativos avaliados, $57(64,8 \%)$ possuíam parentes presentes. A identificação das ligações familiares para boa parte desses cativos, sobretudo dos filhos mais velhos e dos grupos formados por irmãos órfãos, só foi possível mediante o cruzamento de informações entre o inventário, a lista de matrículas de 1872 e os assentos de batismo da igreja.

Para entender as diferenças entre as partilhas desses dois proprietários é preciso considerar, inicialmente, dois fatores: o primeiro diz respeito ao momento histórico em que cada um daqueles senhores morre — um em 1869 e o outro em 1883. No intervalo entre essas duas mortes foi promulgada a Lei de 1871, que, entre outras coisas, proibiu a separação de casais e de pais e filhos menores de 12 anos, além de ter libertado o ventre escravo tornando "ingênuos" os filhos das cativas nascidos depois da lei. Dessa forma, inexistiam crianças escravas com menos de 13 anos no inventário de 1883, e nenhuma com menos de 15 foi separada da família. O segundo fator a ser observado refere-se às especificidades do ciclo de vida daquelas duas famílias no momento da morte de seus chefes. Como vimos, o capitão Francisco José deixou 
esposa e filhos menores, o que tinha efeitos importantes sobre a forma como se dava a partilha dos escravos. A "meação" da viúva ficou com 125 cativos dos 208 que compunham a herança, ou seja, 60,0 por cento da escravaria, o que favorecia a preservação das famílias escravas. Entretanto, o capricho de entregar crianças cativas aos pequenos herdeiros ensejou a separação de duas crianças de seus pais. No caso de Manuel Joaquim de Moraes, vimos que ele era viúvo e não tinha filhos menores de 21 anos.

Posterior à Lei de 1871 e à matrícula geral de 1872, mas anterior à década de 1880, temos o inventário de D. Maria Luiza de Souza Aranha (Viscondessa de Campinas) aberto em agosto de $1879 .{ }^{13}$ Ela já era viúva de Francisco Egídio de Souza Aranha, com quem teve 11 filhos, três deles falecidos antes dela. Todos os seus filhos eram casados, e somente os falecidos deixaram (juntos) 22 filhos (netos da inventariada), muitos deles menores de 21 anos, os quais deviam partilhar as heranças que cabiam a seus pais (legítima avoenga). Entretanto, quase todos os escravos foram repartidos entre os oito filhos vivos da Viscondessa.

A lista de avaliação descreveu 226 escravos, mas foram partilhados efetivamente 217, uma vez que nove cativos foram libertados por herdeiros durante a partilha. Destes, oito mulheres receberam liberdade sem condição e um homem foi alforriado com a condição de servir durante três anos o herdeiro que o libertou. Esse liberto tinha 32 anos, enquanto as idades das mulheres libertadas variavam entre 25 e 56 anos, cinco das quais possuindo mais de 40 anos. Entre as três escravas abaixo dessa idade havia uma viúva de 37 anos, libertada pelo herdeiro Martim Egídio de Souza Aranha, e duas solteiras de 25 e 37, alforriadas por Joaquim Egídio de Souza Aranha (Visconde de Três Rios), ambos filhos da inventariada. Estas duas últimas eram Joana bordadeira e Emiliana, que já haviam sido alforriadas no testamento de D. Maria Luiza, com a condição de servirem ao próprio Joaquim Egídio durante quatro anos. Portanto, ele apenas abriu mão do tempo de serviço daquelas libertas a que tinha direito. Generosidade relativa, considerando-se que foi para ele que a Viscondessa deixou todo o remanescente da terça que ultrapassou os 234 contos de réis, além dos 54 contos que couberam a cada um dos 11 herdeiros como "legítima materna"."

Como nas duas partilhas vistas anteriormente, nesta também não houve separação de nenhum casal escravo. Quanto às crianças, a Viscondessa, em seu testamento, deixou três escravos menores de 12 anos como legados a dois de seus netos e a um parente da família. A "crioulinha” Fermiana, de 9 anos, foi legada a sua neta Maria, com a recomendação de que "se falecer essa crioula 
antes de a legatária a receber, será substituída por outra que lhe deixo a sua escolha, de idade de 7 para 8 anos". ${ }^{15}$

Fermiana não faleceu antes da abertura do inventário, porém, houve uma confusão na determinação da sua identidade, já que na matrícula de 1872 ela fora registrada como "Firmina, filha de Fernando e Maria", quando na verdade, segundo o inventariante, o nome de seu pai era Firmino, e o dela, Fermiana. Para tentar solucionar tal questão, solicitaram a certidão do assento de batismo da menina e descobriram que tal registro não existia nos livros paroquiais destinados aos assentos de batismos de escravos. Foram encontrá-lo num livro de assentos de batismos de pessoas livres. Os pais se apresentaram como os libertos Firmino de Souza Aranha e Maria de Souza Aranha. Ao que parece, Firmino era de fato liberto, enquanto Maria teria alcançado a liberdade mediante o fundo de emancipação "tempos depois" do nascimento de Fermiana. Resumindo: ao final do inventário, em junho de 1880, o Juiz decidiu que "havendo necessidade de verificar a sua identidade, atenta a discordância de nome que há em frente ao da matrícula, ficará para ser atendida na sobrepartilha”.

Todavia, não encontramos na sobrepartilha iniciada em outubro em 1880 nenhuma menção ao caso de Fermiana. Talvez o inventariante tenha desistido e substituído essa escrava por outra, como determinara sua mãe, em caso de morte, ou talvez tenha entregado à legatária (sua sobrinha) o valor de Fermiana em dinheiro.

O pardinho Jonas, filho da parda Maria "conhecida como Mariquinha", foi deixado ao neto Alberto. Em 1879, Jonas tinha 9 anos de idade, segundo a matrícula. No decorrer do inventário, descobrimos que antes de morrer D. Maria Luiza decidira alforriá-lo. Assim, o legado foi cumprido com a entrega do valor daquele pardinho em dinheiro ao legatário.

Por fim, o menino Vicente, de 9 anos, foi o terceiro escravinho legado no testamento. Ele era filho dos escravos José e Francisca, que na partilha dos bens ficaram com o herdeiro Pedro Alcântara de Souza Aranha, neto da inventariada. No julgamento da partilha, ao final do inventário, o Juiz determinou que Vicente fosse "conservado em companhia de seus pais até perfazer a idade legal, devendo então ser entregue ao legatário, dando-se de tal a este cumprimento a verba testamentária de harmonia com a lei que rege a espécie”.

Dessa forma, a lei parece ter sido cumprida, muito embora não tenhamos conseguido saber sobre o destino da escrava/livre Fermiana. É interessante notar que quando a Viscondessa mandou redigir seu testamento, em abril de 1875, a lei proibindo a separação de escravos menores de 12 anos de 
seus pais já existia. Não obstante, ela distribuiu, como legado, escravos que na época tinham cerca de 5 anos de idade. É pouco provável que ela desconhecesse uma lei que causou tanto impacto na sociedade escravista da segunda metade do século XIX, como a lei de 28 de setembro de 1871. Uma hipótese para explicar sua atitude está relacionada a uma concepção senhorial de domínio, que conferia aos senhores de escravos a prerrogativa de determinar os destinos de sua propriedade sem a interferência de terceiros, no caso, o Estado Imperial e suas leis. Ao mesmo tempo, devemos considerar que, ao redigir suas disposições de última vontade, a Viscondessa preocupou-se apenas em presentear alguns netos com escravinhos de mesma idade, deixando para seus herdeiros a preocupação e a tarefa de cumprir sua vontade em conformidade com as determinações legais vigentes no momento de sua morte.

Nas propriedades ora estudadas, não detectamos nenhuma separação de casal de escravos por ocasião da morte do senhor e partilha dos bens. Porém, a separação de duas crianças de 4 e 8 anos, em 1869, revelou um dos limites para a prática ou o costume de preservar as famílias cativas nas grandes posses: a doação de crianças escravas a herdeiros com idades próximas. Como vimos, isso aconteceu nas duas maiores propriedades analisadas, ambas com mais de duzentos cativos. Muito embora, na maioria dos casos, os herdeiros das crianças e dos pais delas morassem juntos ou o juiz tenha ordenado a manutenção dos filhos junto aos pais até a idade legal, podemos considerar que a quebra dos laços de filiação não estava totalmente restrita às partilhas das pequenas posses, ainda que fosse mais freqüente nelas. Mesmo na ausência do fator econômico, que muitas vezes redundava na separação de familiares nas escravarias menores, havia, nas grandes propriedades, o risco da separação de crianças cativas oferecidas como propriedade e companhia aos pequenos herdeiros brancos.

De qualquer maneira, as poucas separações detectadas nos fazem crer que elas constituíam a exceção que confirmava a regra da manutenção dos núcleos familiares unidos, mesmo antes da Lei de 1871. Surge, neste ponto, a questão: será que tal regra se aplicava apenas à fase posterior à abolição do tráfico de africanos, em 1850? Teria sido tal prática ensejada por uma preocupação senhorial em relação à promoção da reprodução natural de sua propriedade, tendo em vista a alta nos preços dos cativos, na segunda metade do Oitocentos? Para tentar responder a estas perguntas, passamos agora a observar algumas partilhas ocorridas na primeira metade do século XIX, quando o tráfico de africanos ainda despejava grande quantidade de cativos nas plantações e engenhos da região. 
Quando o Capitão-mor Floriano de Camargo Penteado faleceu, em 1838, foram avaliados em seu inventário 126 escravos. Destes, 66 compuseram a meação da viúva, 58 foram distribuídos entre os herdeiros, um foi libertado e outro legado na terça (em testamento). Analisando a partilha dos cativos, descobrimos que cinco crianças com menos de 12 anos de idade foram separadas de seus pais e, mais uma vez, nenhum casal foi separado. Dois núcleos familiares foram afetados pela distribuição de seus membros entre herdeiros diferentes. O primeiro caso foi o da família de Joaquim Capeta. Ele e sua esposa Clara foram herdados por uma das filhas do capitão-mor, enquanto seus quatro filhos foram parar nas mãos de outros três herdeiros: Vicente, de 7 anos, entrou no pagamento de Joaquim Ferreira Penteado; Luiz, de 5, foi para a meação da viúva, e as mais novas, Mariana e Efigênia, com 3 anos e 6 meses respectivamente, foram dadas a Felipe Neri, um dos filhos do capitão-mor. A outra família dividida naquela partilha de 1838 foi a da pequena Florência, de 3 anos de idade. Seus pais, Joaquina Monjolo e Matheos, fizeram parte da meação da viúva, ao passo que ela compôs o quinhão do herdeiro tenente Antonio Francisco de Andrade.

Em trabalho anterior ${ }^{16}$ analisamos as partilhas referentes a uma outra família senhorial, cujo patriarca morreu no ano de 1846 . Salvador Bueno da Silveira deixou para seus herdeiros 64 escravos. Como nos outros casos estudados, nenhum casal foi separado. Duas crianças, no entanto, tiveram destinos diferentes daquele de seus pais. Os irmãos Sabina, de 11 anos, e Gabriel, de 9, foram separados de seus pais, Bento Congo e Felipa, e de seus outros três irmãos. Enquanto os dois primeiros foram para o herdeiro Camillo Bueno, o restante da família ficou com seu irmão solteiro Antônio Hypólito. Todavia, descobrimos que por ocasião de sua morte, em 1851, ele morava com seu irmão. Portanto, entre 1846 e 1851 aquela família permaneceu unida na mesma fazenda. A partilha de 1851 teria sido uma boa ocasião para a reunião daquela, se todos fossem para as mãos de Camillo. Porém, não foi isso que aconteceu. A família de Sabina e Gabriel (então com 16 e 14 anos, respectivamente) foi herdada por um terceiro irmão chamado Cândido José. Portanto, na prática, não houve a separação nem de casais nem de filhos menores de 12 anos nessas duas partilhas.

Em 1848, faleceu D. Anna Novaes de Camargo, primeira esposa do Capitão Francisco José de Camargo Andrade. No inventário de seus bens foram descritos 134 cativos, entre os quais foi possível identificar 14 núcleos familiares. Todos os herdeiros eram menores de 21 anos e moravam com o capitão, à exceção de uma jovem casada cuja idade o inventário não menciona. 
Assim como nas partilhas vistas anteriormente, não ocorreu nenhuma separação entre cônjuges. Duas crianças, uma de 2 anos e outra de 2 meses de idade, foram formalmente separadas de seus pais. Mais uma vez, elas foram dadas a herdeiros com idades semelhantes, e seus pais compuseram a meação do viúvo inventariante, que por sua vez, era o pai dos pequenos herdeiros. $\mathrm{Na}$ prática, portanto, aqueles escravinhos continuaram vivendo com suas famílias. Entretanto, outras quatro crianças cativas, todas filhas do mesmo casal e dadas a herdeiros menores, viram seus pais, Felizarda e Gaspar, serem entregues a um credor juntamente com outros cativos solteiros. Dessa forma, neste caso, a separação entre pais e filhos ocorreu efetivamente.

Outra possibilidade de partilha ocorrida na primeira metade do século XIX pode ser vista no inventário de Antônio Fernandes de Abreu, marido de Raquel Umbelina de Camargo, falecido em 1844. Além da viúva, o inventariado deixou sete herdeiros, sendo alguns menores de 21 anos. Entre os 21 escravos avaliados, 19 fizeram parte da meação da viúva e os outros dois foram entregues a dois filhos dela. Nenhuma família sofreu separações, ficando todas com D. Raquel Umbelina.

De um modo geral, nota-se que mesmo antes de 1850, quando o comércio de africanos ainda abastecia de mão-de-obra as lavouras do Império, havia a prática de preservação dos casais cativos legalmente constituídos, assim como da maioria dos filhos menores de 12 anos junto aos pais. É plausível pensar, então, que tal prática poderia servir como uma espécie de estímulo à busca do casamento formal por parte dos escravos. Afinal, a expectativa de permanecerem juntos, mesmo depois da morte do senhor e da conseqüente partilha de bens, dava aos casais cativos um bom motivo para desejarem o casamento católico.

Portanto, ao que parece, muito antes de a lei de 1871 proibir a separação de casais e de pais e filhos menores de 12 anos (em qualquer tipo de transmissão de propriedade) ${ }_{17}^{17}$ a prática entre os senhores de escravos de Campinas já era a de preservar esses núcleos familiares nas partilhas, sobretudo os casais. Assim, podemos considerar que aquela lei veio formalizar uma prática já existente desde a primeira metade do Oitocentos.

A intenção aqui não é a de considerar essas partilhas como se fossem uma amostra representativa ou 'típica' daquela sociedade e daquele período. Os casos aqui apresentados devem ser vistos como possibilidades históricas significativas (e não exemplares), que denotam a necessidade de mais estudos sobre o tema, uma vez que vão de encontro àquelas hipóteses gerais aventadas por alguns autores sem base empírica específica. ${ }^{18}$ Um exemplo é o estu- 
do de Alida Metcalf sobre Santana de Parnaíba no século XVIII. Apesar de não analisar partilhas ou inventários, essa autora supõe que a estabilidade das famílias escravas naquela região estava condicionada ao ciclo de vida dos proprietários. Em suas palavras:

o processo da herança reforçava a probabilidade de que as famílias escravas podiam ser estáveis durante a vida de seus senhores. Após sua morte, contudo, escravos que haviam constituído família eram divididos entre os herdeiros e suas famílias separadas. ${ }^{19}$

Mesmo em se tratando de outra região e de outro período, a ausência de base documental para o levantamento de tal "probabilidade" (somada aos resultados que acabamos de apresentar para Campinas no século XIX) nos permite considerar o momento da morte do senhor bem menos 'ameaçador' à manutenção das famílias do que supõe essa autora. Dessa forma, o intuito de nossa análise das partilhas foi o de apontar possibilidades históricas, empiricamente demonstráveis, no sentido de compor um quadro significativo do impacto dos processos de herança sobre a família escrava.

Como vimos, mesmo antes de 1850, os escravos podiam contar com o respeito a seus laços de parentesco, principalmente o do matrimônio, por ocasião da morte de seus senhores. A percepção desse fato por parte dos cativos pode ter funcionado como um incentivo a mais à constituição de famílias, dentro das possibilidades condicionadas pela escravidão. Além disso, tal prática não pode deixar de ser vista como uma espécie de limite (ainda que fixado pelos próprios donos de escravos) ao direito de propriedade dos senhores, no sentido de que estes não podiam dispor de seus "bens semoventes" de maneira completamente aleatória, desconsiderando seus laços de parentesco. No momento de dividir os bens de um finado senhor, fazia-se necessário atentar para as ligações familiares existentes entre os escravos a serem partilhados, a fim de evitar as separações que poderiam ser seguidas de atos de rebeldia ou melancolia como, por exemplo, as fugas e os suicídios.

Muito embora essa análise se restrinja aos núcleos familiares considerando os filhos menores de 12 anos, pudemos notar que à medida que estes últimos passavam dessa idade as separações tornavam-se mais freqüentes, sobretudo entre aqueles com mais de 15 anos. As separações dos filhos mais velhos representaram, com toda certeza, momentos de dor e tristeza para aquelas famílias. Portanto, nossa opção de análise não significa um menosprezo pelo sofrimento causado aos cativos por tais separações, e sim, uma tentativa 
de compreender até que ponto os limites impostos pela lei de 1871 já eram observados pelos senhores, desde a primeira metade do século XIX.

Para a província do Rio de Janeiro tem-se o estudo de Florentino e Góes, que traz uma análise de partilhas de inventários post-mortem para o período entre 1790 e 1835. Observando os destinos de 138 famílias depois da morte de seus senhores, os autores ligam os índices de manutenção e separação dessas famílias de acordo com quatro variáveis: "tamanho dos plantéis", "tipos de famílias" (matrifocais, nucleares com e sem filhos), "origem dos chefes" (crioulos ou africanos) e, por fim, conjuntura (intensidade) do tráfico de africanos. De acordo com suas conclusões, os maiores índices de permanência das famílias de escravos depois das partilhas aconteciam nos "grandes plantéis" (com mais de vinte cativos), preferencialmente, entre famílias nucleares (sancionadas pela norma) com filhos, cujos chefes eram africanos e nos períodos de menor intensidade do tráfico atlântico. "Nestas condições ideais, cerca de 90 por cento das famílias continuavam juntas", afirmam os autores. ${ }^{20}$

No caso de Campinas, estamos estudando o período subseqüente àquele analisado para o agro-fluminense, por Florentino e Góes. Dessa forma, estes autores podem relacionar a freqüência das separações dos núcleos familiares nas partilhas dos inventários com as conjunturas do tráfico de africanos. Para o nosso estudo foi possível comparar os períodos anteriores e posteriores à abolição efetiva do tráfico em 1850 e à Lei de 1871.

Além disso, outras diferenças precisam ser consideradas, como as dimensões das posses observadas e as metodologias utilizadas nos dois trabalhos. Florentino e Góes analisam os destinos de 138 famílias distribuídas em 43 propriedades, 34 das quais possuíam menos de vinte cativos. Para Campinas, todas as fazendas observadas contavam com vinte ou mais escravos, de maneira que os 133 núcleos familiares acompanhados estavam presentes em sete propriedades diferentes. (cf. Tabela). Dessa forma, trabalhando com grandes escravarias, chegamos a uma média de 97 por cento das famílias unidas após a partilha. Enquanto isso, as conclusões daqueles autores apontam para índices de manutenção das famílias que variavam entre 59,4 por cento, para as seis posses na faixa dos 20 aos 49 cativos, e 87,2 por cento, para as três propriedades com cinqüenta ou mais escravos. Portanto, podemos notar que o número de posses com mais de vinte cativos (9) assemelha-se ao usado em nosso estudo (7), no entanto, os percentuais de manutenção das famílias se distanciam em 10 pontos, aproximadamente. 
Tabela - Destinos das famílias ${ }^{\star}$ escravas em sete partilhas, ao longo do século XIX, em Campinas

\begin{tabular}{c|c|c|c|c|c|c}
\hline \multirow{2}{*}{$\begin{array}{c}\text { Ano de abertura } \\
\text { dos Inventários }\end{array}$} & No de escravos & No de famílias & \multicolumn{2}{|c|}{$\begin{array}{c}\text { Famílias } \\
\text { partilhados }\end{array}$} & \multicolumn{3}{|c}{$\begin{array}{c}\text { Famílias } \\
\text { partilhadas }\end{array}$} & \multicolumn{2}{|c|}{$\begin{array}{c}\text { separadas } \\
\text { unidas }\end{array}$} & \multicolumn{2}{|c}{ No } & $\%$ \\
\hline 1838 & 126 & 15 & 2 & 13,3 & 13 & 86,7 \\
\hline 1844 & 21 & 4 & 0 & - & 4 & 100,0 \\
\hline 1846 & 64 & 9 & 0 & - & 9 & 100,0 \\
\hline 1848 & 134 & 14 & 1 & 7,1 & 13 & 92,9 \\
\hline 1869 & 206 & 36 & 1 & 2,8 & 35 & 97,2 \\
\hline 1879 & 217 & 41 & 0 & - & $41^{* * *}$ & 100,0 \\
\hline 1883 & 88 & 14 & 0 & - & 14 & 100,0 \\
\hline Total: & 856 & 133 & 4 & 3,0 & 129 & 97,0 \\
\hline
\end{tabular}

Fontes: Inventários post-mortem, assentos de batismos e casamentos da Paróquia NSCC e matrícula geral de escravos de 1872 .

* No caso das famílias com filhos, foram considerados aqueles com idade até 12 anos.

** Para a determinação do número de famílias presentes na partilhas, além das listas de avaliação dos Inventários, foram utilizadas as informações dos assentos de batismos e casamentos e, quando possível, das cópias da matrícula geral de escravos. Tal cruzamento de fontes permitiu uma identificação mais precisa dos núcleos familiares.

*** Como vimos, no Inventário de 1879, da Viscondessa de Campinas, não foi possível determinar o destino de uma criança escrava, de nome Fermiana.

As explicações para tal diferença, como vimos, podem estar nos distintos períodos e regiões estudadas, como também nas fontes empregadas. Isto porque, no caso do estudo da região agro-fluminense, foram utilizadas amostras aleatórias de inventários post-mortem, ou seja, sem relações de parentesco entre os proprietários ou o conhecimento das parentelas às quais eles pertenciam. Como vimos anteriormente, conhecer as famílias dos senhores faz toda a diferença para detectar o alcance efetivo das separações nas partilhas. A coabitação entre herdeiros redundava, às vezes, em separações formais dos membros de uma família de cativos, como ocorreu com os irmãos Antônio Hypólito e Camillo Bueno, filhos de Salvador Bueno da Silveira, os quais, em 1846, repartiram a família de Bento Congo e Felipa. Na prática, essa família permaneceu unida, já que aqueles irmãos moraram juntos até a morte do pri- 
meiro. Todavia, para a apreensão destas informações foi preciso analisar todos os inventários disponíveis para aquela família de proprietários. ${ }^{21}$

Além disso, o cruzamento das informações fornecidas pelas avaliações dos inventários com aquelas provenientes de outras fontes, como as listas de matrícula e os assentos de batismos e casamentos de escravos, nos permitiu um mapeamento mais apurado das famílias escravas presentes no espólio. Isso significa que os núcleos familiares da nossa pesquisa possuíam mais membros identificados e, portanto, com risco de serem separados. Assim, os altos índices de manutenção das famílias nas partilhas analisadas para Campinas tornam-se ainda mais significativos. Dessa forma, as diferentes metodologias empregadas nos dois estudos devem ser levadas em consideração no momento da comparação dos resultados.

De qualquer maneira, não obstante todas as diferenças entre os estudos das partilhas para a região agro-fluminense e para Campinas, as conclusões de ambos são bastante semelhantes no que se refere às grandes propriedades. Afinal, a diferença de 10 pontos percentuais nos índices de manutenção das famílias, depois das divisões de bens entre os herdeiros, combina com as especificidades de cada região e período, sem contar a opção metodológica que tende a deprimir tais índices no estudo de Florentino e Góes. Portanto, podese dizer que os resultados das duas análises se reforçam mutuamente, no tocante ao impacto das partilhas de bens sobre o parentesco escravo nas posses com vinte ou mais cativos.

O estudo do impacto da morte do senhor sobre o parentesco escravo (feito a partir da análise das partilhas dos inventários tendo como base metodológica o entrecruzamento de fontes variadas para um mesmo grupo de escravos) tem importância crucial para a compreensão do tipo de expectativa que o escravo podia nutrir em relação aos laços familiares que ele viesse a criar. Dito de outra forma, até que ponto os cativos temiam o momento da divisão dos bens de seu proprietário, vendo nela uma ameaça de separação de seus parentes? O que este artigo procurou mostrar foi, por um lado, a quase ausência de trabalhos que avaliem empiricamente essa questão, e, por outro, a importância de uma opção metodológica que propicie um mapeamento mais completo das relações familiares dos cativos no interior das posses e, por conseguinte, possibilite maior alcance na aferição dos resultados das partilhas, no que diz respeito aos destinos dos escravos. 


\section{NOTAS}

${ }^{1}$ Cf. GRAHAM, Richard. Escravidão, reforma e imperialismo. São Paulo: Perspectiva, 1979 (A $1^{\text {a }}$ edição em inglês foi publicada em 1975); SLENES, Robert W. The demography and economics of Brazilian slavery: 1850-1888. Tese de doutorado, Stanford University, 1976, especialmente os capítulos 9 e 10.

${ }^{2}$ Cf. FERNANDES, Florestan. A integração do negro na sociedade de classe. São Paulo: Ed. USP, 1965; BASTIDE, Roger. As religiões africanas no Brasil. São Paulo: Ed. USP, 1971; CARDOSO, Fernando Henrique. Capitalismo e escravidão no Brasil Meridional: o negro na sociedade escravocrata do Rio Grande do Sul. Rio de Janeiro: Paz e Terra, 1962; COSTA, Emília Viotti da. Da senzala à colônia. São Paulo: Difel, 1966.

${ }^{3}$ FERNANDES, op. cit., p.117.

${ }^{4}$ Ver nota 1 .

${ }^{5}$ Cf. GUTMAN, Herbert G. The black family in slavery and freedom (1750-1925). New York: Pantheon Books, 1976. Esse estudo pioneiro sobre as famílias negras antes e depois da abolição nos Estados Unidos enfatizou a existência e a importância dos laços comunitários e de parentesco entre os escravos e influenciou a historiografia brasileira sobre esse tema. Segundo Gutman, a formação e a estabilidade das famílias escravas estavam diretamente ligadas ao ciclo de vida dos proprietários.

${ }^{6}$ Serão observados nesta análise os destinos das famílias nucleares, ou seja, aquelas compostas por casais sem filhos, casais com filhos, mães solteiras ou viúvas com filhos, pais solteiros ou viúvos com filhos e, ainda, por irmãos órfãos. Optamos por considerar a separação de filhos com até 12 anos de idade, tendo em vista que foi essa a idade adotada pela Lei de 28.09.1871, para proibir a separação de famílias em partilhas ou qualquer outro tipo de transmissão de propriedade. Dessa forma, procuraremos avaliar até que ponto essa lei veio formalizar uma prática já existente entre os proprietários, desde a primeira metade do Oitocentos.

${ }^{7}$ Cf. SLENES, Robert W. A formação da família escrava nas regiões de grande lavoura do Sudeste: Campinas, um caso paradigmático no século XIX. População e família. São Paulo: Cedhal, v.1, n.1, p.9-82, 1998.

${ }^{8}$ SLENES, Robert W. Na senzala, uma flor: esperanças e recordações na formação da família escrava, Brasil, Sudeste, século XIX. Rio de Janeiro: Nova Fronteira, 1999, p.72.

${ }^{9} \mathrm{CMU}, \mathrm{TJC}, 3^{\circ}$ Ofício, caixa 320, doc. 7117, Inventário post-mortem do Capitão Francisco José de Camargo Andrade, ano 1869.

${ }^{10}$ Os parágrafos $7^{\circ}$ e $8^{\circ}$ do art. $4^{\circ}$ da Lei no 2.040, de 28.09.1871, estabelecem que: "Em qualquer caso de alienação ou transmissão de escravos é proibido, sob pena de nulidade, separar os cônjuges, e os filhos menores de 12 anos, do pai ou da mãe. Se a divisão de bens entre herdeiros ou sócios não comportar a reunião de uma família, e nenhum deles prefe- 
rir conservá-la sob o seu domínio, mediante reposição da quota-parte dos outros interessados, será a mesma família vendida e o seu produto rateado". Cf. NEQUETE, Lenine. Escravos e magistrados no Segundo Reinado: aplicação da Lei $n^{\circ} 2.040$, de 28 de setembro de 1871. Brasília: Fundação Petrônio Portela, 1988, p.154.

${ }^{11}$ De acordo com os assentos de batismo dos escravos de Manuel Joaquim de Moraes, 39 bebês nasceram nos anos posteriores à matrícula geral de 1872 e anteriores à partilha de 1883. Eram os ingênuos libertados pelas disposições da Lei de 28 de setembro de 1871 (Lei do Ventre Livre) e, como tais, não podiam ser avaliados no inventário.

${ }^{12}$ A expressão 'membros' refere-se a filhos e a irmãos, já que alguns grupos familiares eram formados apenas por irmãos, cujos pais já haviam falecido.

${ }^{13}$ CMU, TJC, $3^{\circ}$ ofício, caixa 351, processo 7359, Inventário post-mortem de D. Maria Luiza de Souza Aranha (Viscondessa de Campinas), ano 1879, 2 v.

${ }^{14} \mathrm{O}$ cálculo e a divisão da herança aconteciam da seguinte forma: somados todos os bens deixados pelo inventariado tinha-se o "monte mor" ou valor bruto da herança. Descontadas as dívidas do falecido e as despesas do inventário, chegava-se ao "monte menor" ou "monte partível". A forma como se dava a partilha desse valor líquido da herança dependia, basicamente, de dois aspectos: da existência ou não de cônjuge sobrevivente, e da existência ou não de testamento. Como vimos, quando o inventariado deixava um cônjuge, este tinha direito à metade do "monte partível”, a chamada "meação". Quando isso não acontecia, o valor líquido da herança deveria ser dividido em partes iguais entre os filhos do inventariado. Porém, era freqüente, sobretudo entre as famílias abastadas, a confecção de testamentos nos quais o futuro defunto podia dispor como bem entendesse de 1/3 daquele "monte partível”. Assim, através das disposições de última vontade, o testador podia, por exemplo, deixar legados a parentes mais distantes, amigos, afilhados e escravos, bem como conceder alforrias, distribuir esmolas aos pobres, recomendar o tipo de funeral que gostaria de ter e determinar o número de missas que deveriam ser rezadas por sua alma. Por fim, o testador decidia o que deveria ser feito do "remanescente da terça", isto é, da quantia que porventura sobrasse depois do cumprimento de suas disposições. Portanto, nestes casos, apenas os outros 2/3 do monte partível eram divididos em parte iguais entre os herdeiros necessários, as chamadas "legítimas” maternas ou paternas.

${ }^{15}$ CMU, TJC, $3^{\circ}$ ofício, caixa 351, processo 7359, Inventário post-mortem de D. Maria Luiza de Souza Aranha (Viscondessa de Campinas), ano 1879, 2 v. Cópia do Testamento.

${ }^{16}$ ROCHA, Cristiany Miranda. Histórias de famílias escravas: Campinas, século XIX. Campinas: Ed. Unicamp, 2004, p.103-20.

${ }^{17}$ No que se refere à separação de familiares cativos através de vendas, já havia o Decreto $\mathrm{n}^{\circ} 1.695$, de 15.09.1869, que no Artigo $2^{\circ}$ previa que: "Em todas as vendas de escravos, ou sejam particulares ou judiciais, é proibido, sob pena de nulidade, separar o marido da mulher, o filho do pai ou mãe, salvo sendo os filhos maiores de 15 anos" (Collecção das leis do Império do Brasil, Rio de Janeiro, typ. Nacional, 1869, p.129-30). 
${ }^{18}$ Cf. METCALF, Alida. Vida familiar dos escravos em São Paulo no século XVIII: o caso de Santana de Parnaíba. Estudos Econômicos, n.2, v.17, p.229-43, 1987; COSTA, Iraci Del Nero da, SLENES, Robert W. \& SCHWARTZ, Stuart B. A família escrava em Lorena (1981), Estudos Econômicos, n.2, v.17, p.245-95, 1987. De um modo geral, esses estudos buscam enfatizar a relação entre fatores econômicos presentes na vida dos proprietários e os seus efeitos sobre a formação e manutenção dos laços familiares entre os cativos. Ambos consideram o momento da morte do senhor e da conseqüente partilha de bens como uma ameaça à estabilidade das famílias escravas. A primeira autora não apresenta nenhuma evidência empírica para a hipótese, enquanto os autores do segundo artigo lançam mão da análise do volume de escravos comprados, vendidos, doados ou havidos por herança, de acordo com a faixa de tamanho do plantel, em 1801, no município de Lorena. Eles concluem que a maior parte $(77,3 \%)$ desses cativos era oriunda dos plantéis com até 9 escravos, e "considerando-se que tais escravistas detinham 425 dos 912 cativos, vê-se que os fatores desestabilizadores atuaram diferencialmente, afetando $12,0 \%$ da escravaria alocada na faixa de tamanho inferior (1-9 cativos) e apenas 3,1\% dos cativos pertencentes aos proprietários de maior porte (10-41 escravos)". Todavia, não é possível saber se aqueles escravos vendidos, doados ou havidos por herança foram de fato separados de algum familiar nessas transações. Somente uma análise quantitativa de partilhas poderia fornecer uma base mais segura para testar tais hipóteses.

${ }^{19}$ METCALF, Vida familiar dos escravos..., p.238.

${ }^{20}$ FLORENTINO, Manolo \& GÓES, José Roberto. A paz das senzalas: famílias escravas e tráfico atlântico, Rio de Janeiro, 1790-1850. Rio de Janeiro: Civilização Brasileira, 1997, p.121.

${ }^{21}$ Em artigo recentemente publicado, Motta e Valentin analisam a partilha de um inventário aberto no ano de 1819, em Apiaí (SP). Cruzando as informações desse inventário com aquelas fornecidas pelos inventários de dois familiares da proprietária em questão, além de registros de casamentos e listas nominativas, os autores concluem que a distribuição dos escravos entre os herdeiros podia sofrer alterações depois do fim do inventário. Tais mudanças configuravam espécies de "reajustamentos quase imediatos entre os herdeiros, no que tange à alocação dos cativos", e tendiam a reduzir a incidência de separações entre familiares. Cf. MOTTA, José Flávio \& VALENTIN, Agnaldo. A estabilidade das famílias em um plantel de escravos de Apiaí (SP). Afro-Ásia, n.27, p.161-92, 2002. Juntamente com meu livro (ROCHA, Histórias de famílias escravas, 2004), esse artigo reforça a importância da análise de partilhas por meio do cruzamento de fontes variadas para uma mesma propriedade. 